\title{
UNA APROXIMACIÓN A LA IDEA DE “CONSTITUCIÓN ECONÓMICA” Y SUS ALCANCES EN LA CONSTITUCIÓN CHILENA ${ }^{1}$
}

\section{AN APPROACH TO THE IDEA OF "ECONOMIC CONSTITUTION" AND ITS \\ SCOPE IN THE CHILEAN CONSTITUTION}

Christian Viera Álvarez ${ }^{2}$

Jaime BASSA MERCADO 3

Juan Carlos FerRadA BóRQuez ${ }^{4}$

RESUMEN: La Constitución es una norma con techo ideológico abierto que se funda en acuerdos entre diferentes cosmovisiones. Por lo mismo, será un espacio cuyo elemento esencial es definir entre todos el "mínimum constitucional" de reglas y principios que determinan las bases del sistema constitucional. En tal contexto, en este trabajo se analizan los alcances que tendría la idea de "Constitución económica", como marco de opciones legislativas en esta materia, especialmente en el ámbito de la Constitución chilena vigente. A estos efectos, se propone un giro hermenéutico en la tradicional construcción que realizan la doctrina y la jurisprudencia en esta materia, partiendo del supuesto de que el concepto es contingente y se desarrolla bajo un lenguaje equívoco. La apertura de los conceptos constitucionales unida a una lectura dinámica de la sociedad y la Constitución permiten que la interpretación pueda ir adaptándose a las cambiantes circunstancias sociales, políticas o económicas.

Palabras claves: Constitución económica, mercado, Estado, interpretación.

ABSTRACT. The Economic Constitution is a concept with an ideological opened roof, based on different worldviews agreements. Therefore, it is essential component is the definition of the "constitutional minimum" of rules and principles of the political and economic system. This paper analyzes the traditional conception on the Chilean Economic Constitution, to end up proposing a change on the traditional constitutional doctrine and jurisprudence, based on the open ended meaning of this concept, actually in constant social development. Both open ended concepts and the constant

\footnotetext{
${ }^{1}$ Artículo recibido el 21 de enero de 2015 y aceptado para su publicación el 27 de julio de 2015.

${ }^{2}$ Doctor en derecho. Profesor Escuela de Derecho, Universidad de Valparaíso, christian.viera@uv.cl.

${ }^{3}$ Doctor en derecho. Profesor Escuela de Derecho, Universidad de Valparaíso, jaime.bassa@uv.cl.

${ }^{4}$ Doctor en derecho. Profesor Escuela de Derecho, Universidad de Valparaíso, juancarlos.ferrada@uv.cl.
} 
Esta revista forma parte del acervo de la Biblioteca Jurídica Virtual del Instituto de Investigaciones Jurídicas de la UNAM

social evolution on its definition, allows an interpretation that coincides with the characteristic dynamism of contemporary societies.

Keywords. Economic Constitution, Market Economy, State, Interpretation.

SUMARIO: I. Introducción. II. La Constitución económica. III. La Constitución económica chilena. IV. Propuesta de reinterpretación de la Constitución económica chilena. V. Conclusiones. VI. Bibliografía.

\section{INTRODUCCIÓN}

Toda Constitución es fruto y expresión de una lectura política de la realidad social. En las democracias occidentales, el cauce ordinario para esta interpretación tiene en las ideologías a uno de sus referentes. Éstas proponen una explicación acerca de la estructura social, del rol de las personas al interior de ella y procuran una organización conforme a los paradigmas que sirven de fundamento a su propia cosmovisión. Propugnan, en competencia práctica y teórica con otras, una manera de concebir las formas del poder político y su vinculación con el sujeto $y$, en general, de organizar las relaciones humanas en un cuerpo político jurídicamente organizado. ${ }^{5}$

En los modelos económicos, las regulaciones jurídicas tienen la condición de un dato más del problema; por el contrario, para el derecho, los contenidos económicos son elementos vinculantes para la construcción de la estructura normativa; ello, aceptando que la racionalidad rectora del impulso organizativo de las sociedades modernas ha sido la económica, supuesto que obliga a atribuir a la economía una contribución esencial de lege ferenda en la construcción de los ordenamientos modernos. Se trata del valor normativo que caracteriza a la teoría económica, entendida como un método más que una doctrina, un instrumento mental, una técnica de pensamiento que permite a su poseedor alcanzar las conclusiones concretas. ${ }^{6}$ Sin embargo, conviene recordar que la economía no se encuentra indemne a los condicionamientos políticos y culturales; por lo mismo, también deviene o puede devenir en propuesta política.

El rol asignado al Estado en la economía ha tenido diversas fases y formas históricas. Siguiendo a Amin, hay una primera etapa mercantilista, previa a la Revolución Industrial, y con hegemonía del capital mercantil en la zona atlántica y zonas de comercio periféricas

\footnotetext{
${ }^{5}$ Brey Blanco, José Luis, “Ideologías políticas y modelo socioeconómico constitucional”, El sistema económico en la Constitución española, XV Jornadas de Estudio de la Dirección General del Servicio Jurídico del Estado, Madrid, Ministerio de Justicia, 1994, p. 85.

${ }^{6}$ García Cotarelo, Juan, “El concepto de Constitución económica y su aplicación a la Constitución española de 1978", El sistema económico en la Constitución española, Madrid, Ministerio de Justicia, 1994, p. 129.
} 
Esta revista forma parte del acervo de la Biblioteca Jurídica Virtual del Instituto de Investigaciones Jurídicas de la UNAM

(América), desde el siglo XVI a comienzos del XIX. Una segunda, el modelo clásico, posterior a la Revolución Industrial y hasta el fin de la Segunda Guerra, en que emergen el Estado liberal y el mercado como agentes reguladores de las relaciones económicas. La tercera, el periodo de posguerra, en que se produce un despegue económico de los sectores periféricos del mundo y un sistema capitalista fuertemente regulado por el Estado en las economías del "primer mundo". Finalmente, la época más reciente, desde 1990, en que la acumulación de transformaciones ha provocado el colapso del equilibrio característico del sistema mundial de posguerras, con economías muy fuertes y grandes sectores de la población mundial marginados. ${ }^{7}$

Optar por una de estas formas o permitir su surgimiento es lo que regula precisamente el ordenamiento jurídico, dando lugar a lo que se denomina una "Constitución económica", en sentido lato.

Con todo, es necesario advertir que una Constitución económica no es neutra, sea en el plano de las ideas como en el plano operativo; por tanto, aunque los temas económicos puedan relacionarse con técnicas para el aprovechamiento de los recursos, beber de una fuente $u$ otra no es indiferente.

En este contexto, la hipótesis a desarrollar es que la Constitución económica no es inmune a condicionamientos políticos, y que, en el caso de la Constitución chilena, estos condicionamientos han favorecido el desarrollo de un modelo caracterizado por una radical abstención del Estado en la economía, por lo que proponemos una reinterpretación de la Constitución económica chilena. Por de pronto, la Constitución económica se funda en una teoría política, en que su orientación responde a una visión del mundo y la sociedad de la comunidad política en un momento determinado. Además, el concepto de Constitución económica es contingente y se desarrolla bajo un lenguaje equívoco. La imposibilidad de predicar certeza y estabilidad de su significación axiológica no implica su inutilidad, puesto que se puede reorientar su comprensión hacia principios alternativos mediante una labor interpretativa. ${ }^{8} \mathrm{Y}$ en esta labor a los jueces les corresponde una función que puede implicar que en ocasiones se encuentren en la frontera para reconducir la interpretación considerando la apertura conceptual y la natural evolución de la

\footnotetext{
${ }^{7}$ Amin, Samir, El capitalismo en la era de la globalización, Buenos Aires, Paidós, 1999, pp. 15 y 16.

${ }^{8}$ Pereira Fredes, E., “Orden público económico: una propuesta de conceptualización”, Derecho y Humanidades, Santiago, Universidad de Chile, núm. 13, 2008, p. 170.
} 
sociedad. ${ }^{9}$ De ahí entonces la importancia de una relectura de la Constitución económica chilena $y$, en específico, del principio de subsidiariedad, que con una lectura parcial y forzada de fuentes, principalmente el magisterio oficial de la Iglesia católica, ha permitido justificar una radical abstención del Estado como agente económico.

A estos efectos, el trabajo se estructura en tres apartados principales y unas conclusiones finales. El primero se enfoca en un análisis conceptual acerca del término "Constitución económica", analizando su contenido, operatividad e interpretación. En el segundo, se analiza la Constitución económica chilena, haciendo algunos avances a la interpretación tradicional en esta materia, especialmente lo relativo al principio de subsidiariedad, y en el tercero, se propone una relectura de la Constitución económica, considerando perspectivas hermenéuticas abiertas y en el contexto de un sistema democrático. Finalmente, se exponen algunas conclusiones generales.

\section{LA CONSTITUCIÓN ECONÓMICA}

\section{Aproximación conceptual}

Con el triunfo y la implantación del espíritu liberal, en los siglos XVIII y XIX, el individuo se rebela contra el sistema corporativo rompiendo las cadenas que dificultaban su libre desenvolvimiento. Frente al monomio industrial, ahora se defenderá la libertad de contratación, trabajo, comercio, industria y circulación. Se preconiza la política abstencionista del Estado, el laissez faire, laissez paser. La iniciativa privada queda transformada en la base de todo progreso social, mientras que la propiedad privada es presentada como el fundamento de una organización social digna. Por ello, el Estado renuncia a intervenir en asuntos considerados ajenos, especialmente los sociales y la actividad económica, para salvar y garantizar la imparcialidad en su función tutelar los derechos individuales. ${ }^{10}$

Efectivamente, las Constituciones liberales del siglo XIX no contienen referencias explícitas sobre una Constitución económica, pues, como señala Bassols, éstas se encuentran implícitas en el texto. Así, al ser éste un tema que pertenece a la esfera de la sociedad, no se considera necesaria la constitucionalización expresa del sistema económico,

\footnotetext{
${ }^{9} \mathrm{Y}$ algo de eso se está observando en Chile con la interpretación que está realizando el TC a propósito de la ley de Isapres. En la sentencia del 1710-10 del TC se advierte que el respeto y promoción de los derechos sociales configuran un criterio hermenéutico vinculante para la generación de políticas públicas -y también para la elaboración de leyes- en áreas sensibles para un mejor desarrollo humano, especialmente de los sectores menos favorecidos de la sociedad.

${ }^{10}$ Ojeda Marín, Alfonso, El contenido económico de las Constituciones modernas, Madrid, Instituto de Estudios Fiscales, 1990, p. 19.
} 
aunque sí establecer algunos derechos y libertades —especialmente, derecho de propiedad y libertad de comercio-, que cumplen la función de crear las condiciones jurídicas ambientales para el desarrollo del capitalismo. ${ }^{11}$ Por ello, bien dice García-Pelayo que "el orden estatal y el orden económico eran considerados como dos sistemas de funcionamiento sustancialmente independientes, cada uno orientado por sus propios fines y realizándose por la operación de leyes de distinta naturaleza (jurídicas en un caso, económicas en otro)". ${ }^{12}$

Conocidas son las consecuencias que provocará la implementación de un sistema liberal marcado por el radicalismo de sus postulados, especialmente en materia social. Ello generará, como se sabe, una crisis de legitimidad del modelo, provocada por el fuerte descontento social. Como consecuencia, a fines del siglo XIX y principios del siglo XX se adoptarán una serie de medidas de política social y económica llevadas a cabo por vía legislativa y administrativa, las que empiezan a tener un sustento constitucional a partir de comienzos del siglo XX, típicamente con las Constituciones de México y Weimar, de 1917 y 1919 respectivamente. $^{13}$

Ya Schmitt se asomaba al término de Constitución en el periodo entreguerras. Sobre las relaciones del Estado con la economía, señalaba que

...naturalmente, toda Economía y toda "Sociedad" como cualquier otra manifestación de la convivencia humana, reclaman una "Constitución", es decir, una ordenación cualquiera, de modo que en otro sentido distinto, impreciso y expuesto a error, puede hablarse de una Constitución social y económica en cuanto se separan entre sí Estado y sociedad, política y economía, y se consideran sectores reales distintos. Ahora bien, semejante "Constitución", ya sea "económica" o "social", no es precisamente la Constitución del Estado. En la organización y en la estructura política del Estado no se valoran estructuras y elementos económicos como tales; pero, además, el ciudadano individual no ocupa su posición política ni ejerce sus derechos cívicos en su condición de sujeto económico, por ejemplo como patrono o como obrero, como productor o como contribuyente, o por razón de otra calidad o prestación

\footnotetext{
${ }^{11}$ Bassols Coma, Martin, Constitución y sistema económico, Madrid, Tecnos, 1988, pp. 21-26. En la misma línea, se puede revisar García-Pelayo, Manuel, "Consideraciones sobre las cláusulas económicas de la Constitución", en García-Pelayo, Manuel, Obras completas, Madrid, Centro de Estudios Constitucionales, 1991, vol. III, pp. 2855 y 2856; Cancio Meliá, Jorge, "La Constitución económica: promesas incumplibles", Revista Jurídica, Madrid, núm. 7, 2002, p. 53.

${ }^{12}$ García-Pelayo, Manuel, op. cit., p. 2856.

${ }^{13}$ Idem.
} 
Esta revista forma parte del acervo de la Biblioteca Jurídica Virtual del Instituto de Investigaciones Jurídicas de la UNAM

económica; para semejante Constitución sigue siendo tan sólo un citoyen y no un producteur. $^{14}$

No obstante, a pesar de establecer una distinción, no propone una dirección que deba abrazar una Constitución, sino que sólo anuncia la distinción.

Sin embargo, este proceso será más acentuado al término de la Segunda Guerra, época en la que se inicia una nueva etapa en el derecho constitucional, fruto de un compromiso político y social, consagrándose normas de principio de carácter declarativo sobre fines sociales, o bien de rechazo del orden económico liberal sin trabas. Así, se incorporan en los textos constitucionales catálogos de derechos sociales, entendidos como prestaciones u obligaciones a asumir progresivamente por el Estado y medidas de nacionalización de sectores productivos, entre otras normas, que pretenden concretar este nuevo rol del Estado y su mayor compromiso con las necesidades económicas y sociales de la población.

No obstante, en los albores del desarrollo del Estado social, en un contexto dominado por la polarización este-oeste (capitalismo y comunismo), algunos economistas ensayan una aproximación conceptual acerca de la Constitución económica, sin definirla expresamente, pero de la cual se pueden deducir su contenido y sus efectos. Unos de los más importantes es Wilhelm Ropke, quien se refiere a la Constitución económica, con el fin de fundamentar su posición liberal frente a los peligros del comunismo. Sostiene que si se quiere garantizar un mundo de libertad y respeto, la economía debe darse en un marco que reúna tales características, porque de lo contrario, un modelo que no responda a estos principios en definitiva acabará con ellos en el ámbito político. Para Ropke, la estructura económica y política son como dos caras de una moneda en que una condiciona la otra. Por ello postula que se trata de una postura ingenua creer que un Estado puede ser totalitario en materia económica sin serlo simultáneamente en el político. ${ }^{15}$

En este nuevo escenario, la Constitución adquiere una nueva fisonomía, no llegando a plasmar una imagen fija del orden económico-social a alcanzar, sino limitándose a configurar un marco amplio de principios, cuyo programa corresponde desarrollar progresivamente a los poderes públicos, con el impulso de partidos políticos y la presión de las fuerzas sociales. Se genera así la convicción de que a través de la extensión y

\footnotetext{
${ }^{14}$ Schmitt, Carl, La defensa de la Constitución, Madrid, Tecnos, 1983, p. 163.

${ }^{15}$ Citado en García Belaunde, Domingo “La Constitución económica peruana”, Teoría y práctica de la Constitución peruana, Lima, Ediciones JV, 1993, t. II, p. 55.
} 
Esta revista forma parte del acervo de la Biblioteca Jurídica Virtual del Instituto de Investigaciones Jurídicas de la UNAM

participación en el poder político la comunidad podrá hacer frente de sus necesidades colectivas, asumiendo el Estado un rol protagónico en la satisfacción de éstas. ${ }^{16}$

Tratándose de un concepto para la Constitución económica, muchos autores han ensayado algún concepto que permita comprender el fenómeno de la Constitución económica: definiciones formales y descriptivas y otras de contenido material y preceptivo. ${ }^{17}$ Sin embargo, en sintonía con lo que sostenemos en este trabajo, García Pelayo es quien de mejor manera describe lo que debemos entender actualmente por Constitución económica. Este autor atribuye a Eucken como el primero que empleó el concepto que nos ocupa, y señala que son

...las normas básicas destinadas a proporcionar el marco jurídico fundamental para la estructura y funcionamiento de la actividad económica o, dicho de otro modo, para el orden y proceso económico. Tales normas sirven de parámetros jurídicos básicos para la acción de los actores económicos públicos y privados, y pueden ser enunciación de principios y valores directivos orientadores de la acción, o pueden tener formulación y garantías más rigurosas. ${ }^{18}$

Vemos que en este caso se esfuerza por dotar de contenido formal y material a su conceptualización.

Cotarelo señala que las críticas al concepto de Constitución económica confluyen en señalar que tal concepto es deudor de la separación teórica entre Estado y sociedad, separación en la que la Constitución económica se contrapone a la comunidad política dentro del todo social. Se trata de posiciones críticas que al abordar el concepto que estamos analizando desde planteamientos jurídicos positivos exigen la localización del corpus normativo regulador del ámbito económico. Corresponderá entonces al legislador elevar la realidad económica a la condición de derecho, pero en la convicción de que aquélla es un hecho que el legislador no crea, sino que el pensamiento económico "conoce"

\footnotetext{
${ }^{16}$ Bassols Coma, Martin, op. cit., p. 41.

${ }^{17}$ Esta distinción está tomada de Herrero de Miñón, Miguel, “La Constitución económica: desde la ambigüedad a la integración", Revista Española de Derecho Constitucional, Madrid, núm. 57, septiembre-diciembre de 1999, pp. 11 y 12. También pueden verse otras definiciones en Bidart Campos, German, “La Constitución económica (un esbozo desde el derecho constitucional argentino), Cuestiones Constitucionales, México, núm. 6, 2002, p. 4; Quadra-Salcedo, Tomás de la, “La Constitución económica de España”, en Alzaga Villamil, Oscar, Comentarios a la Constitución española de 1978, Madrid, Cortes Generales, Editoriales de Derecho Reunidas, 1996, p. 21; Cantaro, Antonio, "El declive de la «Constitución económica del Estado social»”, en García Herrera, Miguel (dir.), El constitucionalismo en la crisis del estado social, Bilbao, Universidad del País Vasco, 1997, p. 153; García Echevarría, Santiago, “El orden económico en la Constitución”, Libre Empresa, Madrid, núm. 8, 1978, p. 16; Cancio Meliá, Jorge, op.cit., pp. 52 y 53.
}

${ }^{18}$ García-Pelayo, Manuel, op. cit., p. 2857. 
y el derecho "reconoce". Sin embargo, la heterogeneidad de contenidos así recogidos en la Constitución obligaría a admitir el quiebre del principio de unidad de la Constitución. ${ }^{19}$ Entender la Constitución económica en un sentido jurídico-positivo priva al concepto de toda su viabilidad, ya que proporciona elementos críticos para su negación, o conduce a un contradictorio concepto de Constitución jurídico política. Por ello, postula que la Constitución económica es la proyección normativa implicada en la opción por un determinado sistema económico. Se trata no de aceptar en el concepto un conjunto jurídico-positivo definitorio de un orden económico determinado, sin un compromiso normativo dimanante de un modelo económico "descubierto" por el conocimiento de la economía. Agrega, entonces, que siendo orden económico una "realidad natural descubierta", su conocimiento es creciente e indefinido. Por ello, el conocimiento de esta realidad adquiere una función normativa respecto del orden jurídico que pretende implementarla. Por consiguiente, a un determinado conocimiento económico corresponderá una única construcción jurídica, susceptible de compatibilizar el orden "descubierto" de la economía con la máxima garantía posible de libertad económica individual que el derecho debe propiciar. ${ }^{20}$

Esta crítica no esconde que la Constitución económica deba asumir un determinado modelo. Además, parte de un postulado autoritario que trata de imponer: la economía se descubre, y sólo hay que tratar de ver cómo es su funcionamiento; es cierto que puede tratarse de un tipo de conocimiento aplicado, mas eso no obsta a que las reglas de la economía sean dinámicas, lo mismo que la actuación que en ella corresponde a sus actores. Ese es el punto. Una Constitución económica se encuentra en una Constitución, que es fruto del pacto político de los ciudadanos y dotada de legitimidad democrática; un modelo económico, por tanto, no está ajeno a las limitaciones que el soberano político quiere materializar en su máxima norma. Si bien es cierto que seguridad y estabilidad son deseables para una sana convivencia democrática, ello no obsta a que se puedan dar distintos niveles de graduación en una Constitución económica, atendidos los perfiles que son sancionados en cada momento histórico por el pueblo. ${ }^{21}$

\footnotetext{
${ }^{19}$ García Cotarelo, Juan, op. cit., p. 132.

${ }^{20}$ Ibidem, p. 137.

${ }^{21}$ La relación entre Constitución y democracia cuenta con abundante literatura. No es tema de este trabajo desarrollar los criterios de legitimación de una Constitución; sin embargo, compartimos la tesis de que la democracia no sólo es instrumental al sistema político, sino sobre todo fuente de legitimidad. Sobre el punto, entre muchas obras. Aragón, Manuel, Constitución y democracia, Madrid, Tecnos, 1989, pp. 25-63; Böckenförde, Ernest, "El poder constituyente del pueblo. Un concepto límite del derecho constitucional”, en Böckenförde, Ernest, Estudios sobre el Estado de derecho y la democracia, Madrid, Trotta, 2000, pp. 159-180; Cascajo Castro,
} 
Al mismo tiempo, es necesario señalar que la Constitución económica —como la entendemos hoy - es fruto de la emergencia histórica que se da, principalmente tras la Segunda Guerra y es fruto de una reacción a un liberalismo radical del siglo XIX. Además, destaca la distinción que realizan algunos entre una Constitución económica formal y otra material, en que la primera se refiere al orden constitucional expreso en materias económicas, y la segunda es el sistema complejo que relaciona a la economía con el derecho.

En este contexto, el concepto de Constitución económica se identifica con los términos "orden económico", "sistema económico" o "modelo económico"22 —aunque superándolos conceptualmente- ${ }^{23}$ en que más que un contenido y ordenación sistemática de la Constitución, son determinados tópicos que conectan a la economía con el derecho. Entre éstos destacan ciertos derechos y opciones de política económica que puede acoger o rechazar un texto constitucional, los que dan un contenido más o menos neutro a la Constitución frente a un determinado modelo.

\section{Contenido de una Constitución económica}

Es evidente que desde mediados del siglo XX existe una cierta convicción en la sociedad de la inexistencia real de una mecánica autorregulación de la economía en virtud de las leyes económicas del mercado, que en su momento casi fueron equiparadas a las leyes que explican los fenómenos de la naturaleza. Al contrario, se reconoce la existencia de una pluralidad de centros de poder económico, los que no han evitado crisis, desequilibrios, desigualdades y concentración de poder, generando a su vez mayores desequilibrios, inquietudes e injusticias sociales. Ello ha provocado que a la iniciativa económica controlada socialmente por el mercado se añada la actividad económica del Estado, que asume una actitud activa de participación en el proceso económico, mediante una gama de instrumentos de intervención económica. ${ }^{24}$

José Luis, "El Estado democrático: materiales para un léxico constitucional español", Revista Española de Derecho Constitucional, Madrid, núm. 69, 2003, pp. 115-138; Kalyvas, Andreas, "Soberanía popular, democracia y el poder constituyente", Política y Gobierno, México, vol. XII, núm. 1, 2005, pp. 91-124; Lassalle, Ferdinand, ¿Qué es una Constitución?, Barcelona, Ariel, 1997; Hesse, Konrad, "Concepto y cualidad de la Constitución”, en Hesse, Konrad, Escritos de derecho constitucional, Madrid, Centro de Estudios Constitucionales, 1983, pp. 16-22.

${ }^{22}$ Alberti Rovira, Enoch, Autonomía política y unidad económica, Madrid, Civitas, 1995, p. 182.

${ }^{23}$ Ferrada, Juan Carlos, "La Constitución económica de 1980. Algunas reflexiones críticas", Revista de Derecho (Valdivia), vol. XI, 2000, pp. 48-50.

${ }^{24}$ Duque Domínguez, Justino, "Iniciativa privada y empresa”, en Sánchez Agesta, Luis (coord.), Constitución y economía, Madrid, Centro de Estudios y Comunicación Económica, 1977, p. 59. 
En este sentido, al modelo clásico de Estado liberal de derecho, que sólo garantiza derechos individuales y limitaciones para el Estado, se impone un nuevo modelo de Estado, el social, que integra en una fórmula unitaria el principio de los derechos individuales expresados en el campo económico por el derecho de propiedad y las libertades de iniciativa económica - con el principio de solidaridad, transformación que supone superar la separación radical entre Estado y sociedad. Así, el Estado deja de ser árbitro neutral de la actividad privada de los particulares, que sólo establece reglas dentro de las cuales los particulares pueden actuar libremente. Al contrario, se hace responsable de que se mantengan las condiciones de las que depende el mercado y la libre determinación de los particulares junto a un equilibrio social. Estas condiciones no son obra de una legalidad natural, que sólo puede ser alterada por los actos de personas; por el contrario, son producidas por la actividad normativa del Estado, cuando el propio proceso de la libertad económica las ha deteriorado. ${ }^{25}$

De ahí que la mayoría de las Constituciones contemporáneas, aparte de su contenido político, pasarán a contener normas que configuran una verdadera Constitución económica, ordenadora de la actividad económica, desarrollada por el sector público o privado. No se trata sólo de regular los derechos económicos y sociales de los ciudadanos, sino también de construir una orgánica genérica que regule la economía nacional, estableciendo sus bases y principios esenciales para su desarrollo. ${ }^{26}$

\section{Las teorías sobre la Constitución económica ${ }^{27}$}

Sin perjuicio de lo antes expuesto, la doctrina sostiene diversos enfoques u opciones que puede seguir el constituyente en el diseño de la Constitución económica, atendida la valoración que se haga de esas reglas y del proceso político en que están inmersas. Así, algunos propondrán la neutralidad político-económica de la Constitución; es decir, plantear que no debe buscarse en la Constitución una respuesta a la organización de la vida económica. La decisión sobre la organización de la economía es una decisión política, y no constitucional, por lo que no hay garantía sobre la permanencia de un marco para la

\footnotetext{
${ }^{25}$ Ibidem, pp. 65 y 66.

${ }^{26}$ Brewer-Carías, Allan, "Reflexiones sobre la Constitución económica”, Revista de Derecho Público, Caracas, núm. 43, 1990, p. 6.

${ }^{27}$ Recogemos propuesta sistemática sobre las teorías propuesta por García Echevarría, Santiago, op. cit., pp. 1720.
} 
actuación económica, ya que una democracia descansa en el relativismo, y no contiene ninguna decisión valorativa. ${ }^{28}$

Otros en cambio postularán que el Estado debe dar un marco de actuación a la economía y ordenar su estructura, por lo que la Constitución económica debe integrar las ideas políticas sobre el orden de la sociedad con las exigencias de organización de la economía (cercano al planteamiento alemán de la economía social de mercado). ${ }^{29}$ Esta posición implica dar un salto cualitativo en la definición del modelo económico, ya que apuntan al establecimiento de reglas que determinan y limitan las opciones políticas en materia económica.

Una tercera postura señala que los derechos fundamentales no sólo son derechos subjetivos, sino normas fundamentales del más alto nivel, por lo que el actuar del Estado consiste en el apoyo a la persona ante una necesidad que se estima fundamental para la realización en cuanto persona, sea en una dimensión preventiva o curativa. Además, un determinado orden económico se mide con la métrica de si corresponde o no a los derechos fundamentales. Por tanto, la Constitución económica se plantea como una correspondencia de las estructuras del orden económico con los derechos en la Constitución: el orden económico está sujeto a los derechos fundamentales, los que suponen un límite en la configuración del orden económico. ${ }^{30}$

Por último, un cuarto postulado recoge la dimensión funcional del sistema económico y social para el logro de los objetivos perseguidos por los derechos fundamentales. Un orden económico se sitúa en una sociedad en un momento concreto y con condiciones reales dentro de las cuales debe realizarse. Entonces, el orden económico debe tener en cuenta el orden real. La relación norma-realidad constituye un problema abierto, pues un desconocimiento de la situación factual puede llevar al vacío de la norma jurídica. ${ }^{31}$

Como se puede observar, pueden existir diferentes modelos de Constitución económica, pues no hay una sola aproximación a este concepto, lo que genera efectos diferentes tratándose de unas u otras. Sin embargo, la categorización expuesta puede ser útil para comprender que en este ámbito no es un espacio para propuestas únicas con pretensiones de universalidad. Se trata más bien de una esfera de discusión racional y apertura a nuevos paradigmas para el desarrollo de una propuesta de Constitución económica.

\footnotetext{
${ }^{28}$ García Echevarría, Santiago, op. cit., p. 17.

${ }^{29}$ Ibidem, p. 18.

${ }^{30}$ Ibidem, pp. 17 y 18.

31 Ibidem, p. 19.
} 
Esta revista forma parte del acervo de la Biblioteca Jurídica Virtual del Instituto de Investigaciones Jurídicas de la UNAM

\section{Operatividad de una Constitución económica ${ }^{32}$}

Determinar el contenido y la utilidad de una normativa constitucional en materia económica no es cosa sencilla, y no puede tratarse de una solución imperativa y categórica, ya que la aproximación a este fenómeno se encuentra condicionada por la "sensibilidad" de quien postula tal o cual orientación. En este sentido, en opinión de García-Pelayo la Constitución económica puede integrarse por más o menos preceptos, sin embargo, se debe contar con al menos tres materias constitutivas del orden económico jurídico: el derecho de propiedad, la forma de relación entre los actores económicos y la distribución de las atribuciones entre el Estado y los actores y entidades económicos de la sociedad. ${ }^{33}$

Tratándose de la propiedad, es una institución susceptible de estructuras concretas muy diferentes, desde la propiedad personal de los bienes hasta la de grandes empresas por acciones, en las que dos momentos constitutivos del concepto de propiedad (dominio sobre la cosa y derecho a los frutos que ella produzca) se encuentran separados. Con todo, si bien la propiedad se encuentra reconocida por las Constituciones occidentales, no puede afirmarse a costa de otros bienes constitucionalmente protegidos, por lo que la interpretación de su contenido sólo puede hacerse en conexión con las otras normas fundamentales y en un momento histórico determinado. ${ }^{34}$

En cuanto a la forma de relación de los actores en la economía, aparece la economía de mercado. Desde luego, existen varios sistemas a los que se identifica con este término, a saber: la economía de mercado libre, la economía social de mercado y la economía dirigida, noción compatible con distintos contenidos estructurales de naturaleza socioeconómica cuya determinación concreta dependerá de las políticas económicas a seguir. ${ }^{35}$

En relación con la distribución de atribuciones entre el Estado y otros actores económicos, García-Pelayo aborda la función del Estado en materia económica. Para este autor, las exigencias de nuestro tiempo han provocado que el Estado incluya dentro de sus potestades las de índole económica, pues constituyen una condición de su existencia, que no sólo interviene en el orden económico mediante leyes y actos administrativos, sino también mediante una acción económica directa (por ejemplo, por medio de empresas, cotizaciones sociales, tributos, su participación en el PIB, inversión en infraestructuras,

\footnotetext{
${ }^{32}$ Una estupenda síntesis del fenómeno constitucional que estamos comentando se puede encontrar en la obra de García Belaunde, Domingo, op. cit., pp. 53-97.

${ }^{33}$ García-Pelayo, Manuel, op. cit., p. 2858.

${ }^{34}$ Ibidem, pp. 2859 y 2860.

${ }^{35}$ Ibidem, pp. 2862-2868.
} 
Esta revista forma parte del acervo de la Biblioteca Jurídica Virtual del Instituto de Investigaciones Jurídicas de la UNAM

desarrollo de políticas destinadas a producir fuerza de trabajo calificada, etcétera). Claro está que la actividad económica del Estado puede tener lugar sin necesidad de que la Constitución lo establezca; sin embargo, es comprensible que se regule jurídicamente, dada la naturaleza dinámica, coyuntural y hasta contingente de la realidad económica. ${ }^{36}$

Y como se trata de una dimensión polémica, desde visiones liberales se relativizan los aportes que puede realizar el Estado como agente económico. Tal vez el autor más representativo de este sector sea Ariño Ortiz. Para él, la esfera de legítima intervención del gobierno en una sociedad libre debe venir justificada por la existencia de un interés público -relacionando el artículo 128 con el 103.1, que afirma que “la Administración Pública sirve con objetividad los intereses generales..."-, la cual debe ser especificada en razones concretas para justificar la intervención empresarial del Estado, que identifica con razones militares, por el carácter estratégico del sector, la envergadura y el elevado riesgo de la inversión o el largo plazo del proyecto que hace que no puedan ser asumidas por el sector privado, etcétera, o bien porque el sector privado no ha sido capaz de alcanzar las dimensiones adecuadas, tanto porque de acuerdo con la planificación del desarrollo nacional el Estado desea forzar la producción o por simplemente por insuficiencia o inexistencia de la iniciativa privada. ${ }^{37}$ Por tanto, la intervención del Estado es claramente subsidiaria, y así lo afirma: "estamos de nuevo ante el principio de subsidiariedad, que sigue vigente en una sociedad libre pese a todos los críticos". ${ }^{38}$

En principio, y como consecuencia del carácter excepcional que tiene la gestión empresarial pública en una economía de mercado, el fin u objeto social de una empresa pública debe delimitar el alcance y extensión de sus actividades, ya que extender éstas a

\footnotetext{
${ }^{36}$ Ibidem, p. 2869. Con todo, especialmente crítico con García-Pelayo se muestra Entrena Cuesta, crítica que le realiza tanto desde un punto de vista histórico-político como jurídico. Desde el punto de vista histórico-político señala que si bien la Constitución española es fruto del consenso, es cierto que los partidos políticos renunciaron a alguno de los principios que conforman el ideario. Desde un punto de vista jurídico afirma que, admitiendo la flexibilidad del sistema, existen algunos preceptos con más relevancia que otros: a su entender, los contenidos en el capítulo II, título I, entre los que figura el derecho a la libertad de empresa en el marco de la economía de mercado, tal derecho deberá ser respetado, en su contenido esencial, por el legislador, ya que vincula a todos los poderes públicos. Consecuentemente, por profundos que sean los cambios, éstos deben reconocer este derecho y asumir los efectos que de tal reconocimiento y preeminencia derivan. Entrena Cuesta, Rafael, "El modelo económico de la Constitución”, id., La empresa en la Constitución española, Pamplona, Aranzadi, 1989, p. 17.

${ }^{37}$ Ariño Ortiz, Gaspar, “La iniciativa pública en la Constitución. Delimitación del sector público y control de su expansión", Revista de Administración Pública, Madrid, núm. 88, 1979, pp. 69-74.

38 Ibidem, p. 75.
} 
Esta revista forma parte del acervo de la Biblioteca Jurídica Virtual del Instituto de Investigaciones Jurídicas de la UNAM

campos no previstos supondría desarrollar una competencia ilegal con las empresas privadas actuantes en dichos campos y un atentado al régimen de economía de mercado. ${ }^{39}$ Y relacionado todo con el artículo 38, el Estado no deberá intervenir como empresa pública si en el campo de actuación de que se trate la iniciativa privada cumple su función productiva y no lo exige un interés general prevalente y cierto. ${ }^{40}$

A lo anterior es necesario señalar que otros autores destacan que la Constitución económica tiene por finalidad principal ya sea la búsqueda de seguridad, ya la afirmación de un programa, o ambas cosas a la vez. Por un lado, las Constituciones se configuran como zonas de seguridad; por ello, algunos elementos del sistema económico que se entienden amenazados por la presión social o propuesta radicales se configuran como “garantía institucional", por ejemplo, las prohibiciones constitucionales al déficit del Estado. Pero, por otro, se produce la utilización de la Constitución para afirmar los programas de reforma social, de ahí que se inscriban en una Constitución métodos y formas para transformar la economía. ${ }^{41}$ Sin embargo, se agrega que existe una tercera motivación para la existencia de una Constitución económica: la tendencia a llegar a un compromiso entre las dos anteriores y afirmar lo que no se piensa hacer, por lo que surge en el derecho constitucional un lenguaje que no es ni descriptivo de lo que existe ni dinámico. Sin embargo, quienes mediante la Constitución económica pretenden satisfacer esas metas no manejan magnitudes económicas reales, sino valores, polémicos y radicales cuando no están sujetos a la más básica de las reglas económicas: el principio de escasez, con lo que la Constitución económica se carga de una doble polemicidad: axiológica y retórica. ${ }^{42}$

Sin embargo, estas fórmulas constitucionales no parecen haber tenido incidencia en la práctica política y jurídica de la Constitución. En unos casos por su equivocidad, en otros porque su significado normativo poco añade al modelo que se deriva del orden económico; en efecto, la Constitución es elemento principal de aquel orden, pero sólo parcial, por lo que se postula la necesidad de un modelo económico determinado en una Constitución, sea implícita o explícitamente, junto a los condicionamientos propios de su inserción en un espacio geográfico y temporal. ${ }^{43}$

\footnotetext{
${ }^{39}$ Ibidem, p. 103.

${ }^{40}$ Ibidem, p. 89.

${ }^{41}$ Herrero de Miñón, Miguel, op. cit., p. 12.

42 Ibidem, p. 13.

${ }^{43}$ Ibidem, pp. 14 y ss.
} 
Como se puede apreciar, las orientaciones políticas condicionan la interpretación de lo que deba ser una Constitución económica. Por de pronto, están los que postulan la apertura de la Constitución y que ésta debe ser neutral. Sin embargo, otros señalan que, por el bien de la convivencia social, no puede haber neutralidad económica. Por su parte, algunos otorgan al Estado un papel corrector de la economía frente a la emergencia de un liberalismo que se quiere imponer sin límites; otros prefieren, en cambio, un rol subsidiario del Estado, retrocediendo incluso a las manifestaciones económicas propias del siglo XIX. Por esto, se puede afirmar que a una Constitución no le es ajena la economía, como no le es ajena cualquier otra parcela de la realidad social. La Constitución, junto con ser norma fundamental, es también norma básica de todo el ordenamiento jurídico.

Ya no sólo es la Constitución política [del Estado] sino la Constitución jurídica (de la nación). Por ello, en el terreno de la economía la constitución de ahora... amplía considerablemente su campo normativo estableciendo los principios rectores del sistema económico y determinando las posiciones que en ese sistema ocupan los sujetos privados y los poderes públicos. La regulación de la economía ha pasado a ser parte, pues, de la materia constitucional. ${ }^{44}$

En todo caso, no caben dudas de que la operatividad de una Constitución económica sea clave para el desarrollo económico de una sociedad. Si bien los efectos concretos dependen de la ideología a la que responda el modelo que proponga un programa político, pareciera que en la dialéctica capitalismo-socialdemocracia, mercado-regulación estatal, una propuesta que relativice el mercado y permita la actuación del Estado como agente económico, es el mejor sistema para el desarrollo pacífico y en libertad de una comunidad.

No obstante, como ha señalado Cancio Meliá, se ha producido en el último tiempo un cierto declive de la Constitución económica del Estado social, producto fundamentalmente del abandono, más fáctico que expreso, de los postulados sociales de las Constituciones europeas. Asimismo, se ha producido un auge de propuestas dirigidas a limitar la capacidad de endeudamiento del sector público o restringir el déficit público, medidas todas que entrañan una mutación constitucional en sentido material. ${ }^{45}$

Con todo, la Constitución económica no tiene las mismas proyecciones hoy que ayer. Sin embargo, las tensiones que produce la intervención del Estado en la economía siguen

\footnotetext{
${ }^{44}$ Aragón, Manuel, “Constitución económica y libertad de empresa”, Estudios jurídicos en homenaje al profesor Aurelio Menéndez, Madrid, Civitas, 1996, t. I, p. 166. Sobre la tensión entre diferentes perspectivas, Gimeno Feliú, José María, "Sistema económico y derecho a la libertad de empresa versus reservas al sector público de actividades económicas", Revista de Administración Pública, núm. 135, 1994, pp. 149-212.

${ }^{45}$ Cancio Meliá, Jorge, op. cit., p. 53.
} 
Esta revista forma parte del acervo de la Biblioteca Jurídica Virtual del Instituto de Investigaciones Jurídicas de la UNAM

vigentes. Y esta oposición a la intervención del Estado en la economía ayer era por una reacción a los socialismos reales; pero hoy, por la falta de una respuesta eficaz a las crisis económicas globales, que no encuentran en el mero orden espontáneo de la economía una respuesta suficiente para su superación y, sobre todo, para que los costos de las crisis no sean soportados por los sectores menos aventajados de la comunidad.

\section{La interpretación de las cláusulas económicas de la Constitución}

Las Constituciones, como se sabe, establecen la regulación básica del Estado, y muchas de sus concepciones no están definidas de antemano, porque se trata de cláusulas abiertas. Conceptos como moral, orden público, buenas costumbres, son concepciones dinámicas, cuyo contenido material será determinado por el intérprete, quien, a pesar de la claridad de los enunciados normativos, está fuertemente condicionado por su contexto histórico y por la evolución que sufren estos conceptos en la sociedad. Frente a estas cláusulas abiertas, hay diversas aproximaciones hermenéuticas que pretenden explicar su significado.

Por de pronto, está el originalismo, escuela de interpretación constitucional que proporciona una especial relevancia al momento constituyente y puede ser clasificada entre una versión moderada y otra radical. ${ }^{46}$ La primera orientación postula la idea de que el espíritu de los constituyentes quedó plasmado en el texto; por ello, siempre hay que tenerlo como marco de referencia; la segunda, el originalismo radical es una reacción crítica a la jurisprudencia de la Suprema Corte de Estados Unidos, durante las presidencias Warren y Burger y sostiene que lo único que ha de regir la interpretación de la Constitución es la voluntad o intención de los constituyentes (original intent); ${ }^{47}$ en la Constitución no hay más que aquello que los constituyentes quisieron incluir y que, en la práctica, incluyeron. ${ }^{48}$

El problema de esta corriente radica en que tiende a la petrificación del derecho y a considerar el ordenamiento jurídico desde una perspectiva estática; tanto así, que la versión más radical del originalismo sostiene que en la labor creativa de los tribunales, lo que hacen los jueces al crear nuevos derechos es imponer sus propias convicciones subjetivas, sin que sea extensible al ordenamiento jurídico general con carácter de precedente.

\footnotetext{
${ }^{46}$ Beltrán de Felipe, Miguel, Originalismo e interpretación, Dworkin vs. Bork: una polémica constitucional, Madrid, Publicaciones de la Facultad de Derecho, Universidad Complutense-Civitas, 1989, p. 51.

${ }^{47}$ Smith, Peter, "How Different Are Originalism and Non-Originalism?", Hastings Law Review, vol. 65, 2011, pp. 711-713. Sobre el contenido del originalismo original, Powell, Jefferson, "The Original Understanding or Original Intent", Harvard Law Review, Estados Unidos de América, vol. 98, 1985, pp. 885-948.

${ }^{48}$ Beltrán de Felipe, Miguel, op. cit., pp. 52 y 53.
} 
Por el contrario, creemos que un adecuado sistema interpretativo debe considerar el carácter evolutivo de la realidad social; por ello, deben aplicarse reglas extensivas y flexibles que permitan su adecuación con el sentido de las normas jurídicas en un contexto histórico/espacial determinado. Una mirada de esta naturaleza no implicaría un desmejoramiento del panorama constitucional o un serio cuestionamiento a la certeza jurídica, sino que actualiza y sincera la relación entre norma y sociedad.

Sobre una propuesta de interpretación extensiva, se ha señalado que

...esta situación se presenta con particular intensidad en las normas constitucionales de principio. En efecto, en tanto éstas son directa manifestación del consenso político que debe representar la Constitución, son las normas que mayor influencia reciben de la evolución de la sociedad. Así, la rigidez constitucional, concepto derivado de la supremacía constitucional, no debe llegar al punto de congelar el contenido material de las normas de principio (por ejemplo, normas de derechos fundamentales, positivación del principio democrático, entre otras), precisamente porque es a través de estas normas que la comunidad actualiza el contenido de su pacto político. ${ }^{49}$

Sin perjuicio de las orientaciones que abogan por destacar el momento constituyente y hacerlo vinculante desde la perspectiva hermenéutica, creemos que es fundamental abrir el proceso de interpretación de las normas y aplicar criterios extensivos que favorezcan la comprensión armónica entre norma y realidad. Y esta actualización no sólo implica reconocer el carácter evolutivo del contenido material de las reglas jurídicas, sino que además se trata de una apertura a los intérpretes de la Constitución; es lo que en lenguaje de Häberle se llama "sociedad abierta de los intérpretes de la Constitución". ${ }^{50}$

Según Häberle, "en los procesos de interpretación constitucional están incluidos potencialmente todos los órganos del Estado, todos los poderes públicos, todos los ciudadanos y los grupos. No hay un numerus clausus de intérpretes de la Constitución". ${ }^{51}$ ¿Por qué? Porque las normas jurídicas surgen para que ocupen un espacio vital de la comunidad, en el ámbito que sea; por ello, quien vive la norma debe interpretarla; la interpretación es una actividad encaminada a la comprensión y explicación de una norma, sin perjuicio de que siempre, al final del proceso hermenéutico hay un intérprete final de última instancia (corte suprema o tribunal constitucional). Sostener una tesis de esta

\footnotetext{
${ }^{49}$ Bassa Mercado, Jaime, La teoría del poder constituyente en la Constitución chilena vigente, tesis para optar al grado de magíster en derecho, Santiago, Universidad de Chile, Facultad de Derecho, 2007, p. 69.

${ }^{50}$ Häberle, Peter, El Estado constitucional, México, UNAM, 2003, pp. 149-161.

${ }^{51}$ Ibidem, p. 150.
} 
naturaleza produce una democratización del proceso interpretativo, sintonizando con una teoría acerca de la democracia. ${ }^{52}$

En la misma línea propuesta por Häberle y profundizándola, Zagrebelsky señala que si existe una norma positiva que ya no responde a los requerimientos de la sociedad producto de un cambio profundo experimentado por ésta, la presión del caso impone la modificación de la norma a fin que se adecue y sintonice con la realidad social, esfuerzo en el que deben participar jueces, legisladores y autores. En efecto, el derecho no puede separarse del ambiente cultural en el que se halla inmerso y erigirse como un sistema normativo independiente y autosuficiente, puesto que es una parte importante del entramado social. ${ }^{53}$ Por lo mismo, no sólo importa el caso, sino que además se trata de aceptar pacíficamente que el ordenamiento no siempre está en condiciones de ofrecer al intérprete una sola respuesta, como tampoco que hay un único método de interpretación, verificándose más bien un pluralismo metodológico, reflejo del pluralismo de nuestra propia cultura. Por lo mismo, se trata de postular un modelo que tome distancia de los clásicos criterios de jerarquización, especialmente como criterio de solución de conflictos entre derechos, porque se han mostrado estériles para dar respuestas satisfactorias a las problemáticas críticas. $^{54}$

Entonces, como señala Zagrebelsky,

...el caso no debe entenderse como un suceso histórico en su dimensión puramente fáctica...

Sino que se trata de un acontecimiento problemático que plantea la cuestión de cómo responder al mismo, de cómo resolverlo en términos jurídicos... para el derecho es algo que debe ser resuelto [en que] la resolución viene exigida por la existencia del problema. ${ }^{55}$

Por tanto, la interpretación no se puede presentar como un sistema abstracto con reglas universales aplicables para todo tiempo y lugar, desconociendo o volviendo la espalda al caso concreto. La pluralidad social en la que nos encontramos inmersos ha generado "la explosión subjetivista de la interpretación del derecho, ya que se ha agotado un cuadro de principios compartidos por la generalidad". ${ }^{56}$

\section{LA CONSTITUCIÓN ECONÓMICA CHILENA}

\footnotetext{
52 Ibidem, p.151.

${ }^{53}$ Zagrebelsky, Gustavo, El derecho dúctil. Ley, derechos, justicia, 5a. ed., Madrid, Trotta, 2003, pp. 133-138.

${ }^{54}$ Ibidem, pp. 134 y 135.

55 Ibidem, p. 136.

${ }^{56}$ Bassa Mercado, Jaime, op. cit., p. 70.
} 
No es novedoso señalar que Chile es un ejemplo paradigmático de cómo las políticas neoliberales se introdujeron en todas las áreas, siendo la educación, la seguridad social y la sanidad -y añadiríamos ahora también el transporte público- ejemplos de cómo los criterios mercantiles pueden colonizar estas áreas. Sin embargo, su implementación han supuesto un elevado coste social, especialmente en la década de los ochenta, y los resultados de esas políticas han permitido una diferencia cada vez más acentuada entre los sectores sociales más acomodados y los menos aventajados. A pesar de las reformas legales que se han introducido, los fundamentos siguen siendo los mismos, por lo que las modificaciones, a pesar de atemperar la radicalidad del modelo original, no han permitido un cambio sustantivo del paradigma neoliberal. ${ }^{57}$

A pesar de no establecer explícitamente un sistema o modelo económico, es evidente que la Constitución chilena ha constitucionalizado una economía de mercado. Esta opción se ve reflejada en diversas disposiciones, como son el establecimiento de la libertad de empresa como un derecho fundamental (artículo 19 núm. 21), la no discriminación en materia económica (artículo 19 núm. 22), la regulación del derecho de propiedad (artículo 19 núm. 24); lo propio ocurre con la determinación constitucional de las materias de ley y su proceso de formación, que "restringe la aplicación de instrumentos de política fiscal que se utilizan junto a políticas monetarias en una economía social de mercado, como es el manejo de impuestos y gastos sean corrientes o de transferencias, privilegiando el equilibrio fiscal y la estabilidad de la moneda". ${ }^{58}$

Con todo, es necesario hacer presentes algunas cuestiones en relación con esta materia.

Lo primero, que la Constitución económica que plantea la Constitución de 1980 excede el establecimiento de un puro "orden público económico" (OPE), como lo ha sugerido la

\footnotetext{
${ }^{57}$ Sobre este punto Atria, Fernando, Veinte años después, neoliberalismo con rostro humano, Santiago, Catalonia, 2013, pp. 33-54.

${ }^{58}$ Guerrero Becar, José Luis, “La libertad para desarrollar actividades económicas del artículo 19 núm. 21 y la Constitución económica", Persona y Sociedad, Santiago, vol. IV, núm. 3, 2000, p. 147. En cuanto a la regulación legal, véase en la Constitución los artículos 63 Núms. 7-9 (materias de ley), artículo 65 núm. 1-3 (procedimiento de formación de la ley) y artículo 67 (Ley de Presupuesto). Incluso este autor señala que “el «triángulo mágico» que reconoce la Constitución, a un nivel de exégesis constitucional es: estabilidad de precios, equilibrio de la cuenta corriente fiscal y crecimiento económico. El elemento sacrificado es el pleno empleo, lo que no implica que no se logre, sino que no puede sacrificarse ni la estabilidad de precios ni el ajuste de la cuenta corriente para lograrlo... todas estas medidas se ajustan claramente al pensamiento monetarista". Guerrero Becar, José Luis, op. cit., p. 155.
} 
Esta revista forma parte del acervo de la Biblioteca Jurídica Virtual del Instituto de Investigaciones Jurídicas de la UNAM

doctrina más tradicional chilena, ${ }^{59}$ ya que no sólo contiene límites indisponibles para el legislador y los privados, sino normas que configuran y ordenan la actividad económica pública y privada en su conjunto. ${ }^{60}$ Así, el concepto mismo de OPE tiene el inconveniente de desdibujar parcialmente el análisis jurídico integral de estas normas, pues se observa esta temática sólo desde la perspectiva del derecho privado, "considerando la intervención reguladora del Estado como una excepción calificada al orden natural impuesto de libre mercado, prejuzgando anticipadamente las conclusiones científicas acerca de la posición jurídica del Estado y sus agentes en el proceso económico" ${ }^{61}$

Lo segundo es que la Constitución, si bien no explícitamente, sus normas consagran una economía de mercado, especialmente atendiendo la protección que dispensa a la libertad de empresa, la estructura del derecho de propiedad, el rol del Estado en la economía y los principios que establecen para las políticas monetaristas. El problema de esta opción no es,

\footnotetext{
${ }^{59}$ Entre muchos véase Dougnac Rodríguez, Fernando, “La garantía constitucional del núm. 21 del artículo 19 de la Constitución en relación con las demás que configuran el "orden público económico»", Gaceta Jurídica, Santiago, núm. 68, 1986, p. 8; Fermandois Vöhringer, Arturo, “El orden público económico bajo la Constitución de 1980", Ius Publicum, Santiago, núm. 4, 2000, pp. 76-78; Avilés Hernández, Víctor, "Orden público económico: noción crítica", Revista de Derecho Público, Santiago, núm. 63, 2001, pp. 335 y 336; Montt Dubournais, Luis, "El orden público económico y la Constitución", Revista de Derecho Económico, núms. 60 y 61, 1983, p. 49; Streeter Prieto, Jorge, "El paradójico orden público económico", Revista de Derecho Económico, núms. 60 y 61, 1983, p. 31; Santa María de la Vega, Raúl, "El orden económico", Revista de Derecho Económico, núm. 6061, 1983, p. 18; Varela del Solar, José Luis, "Subsidiariedad, orden público económico y seguridad nacional en la Constitución de 1980", Revista Chilena de Derecho, Santiago, vol. 16, núm. 2, 1989, p. 386; López Magnasco, Sebastián, Garantía constitucional de la no discriminación económica, Santiago, Editorial Jurídica, 2006, pp. 58-62; López Magnasco, Sebastián, Libertad de empresa y no discriminación económica, Santiago, Cuadernos del Tribunal Constitucional, 2012, pp. 25-40; Soto Kloss, Eduardo, “La actividad económica en la Constitución Política de la República de Chile (La primacía de la persona humana)", Ius Publicum, Santiago, núm. 2, 1999, p. 119; Fermandois, Arturo, Derecho constitucional económico, 2a. ed., Santiago, Ediciones Universidad Católica de Chile, 2006, t. I., pp. 71-72; Guerrero Becar, José Luis, op. cit., pp. 141-142; Guerrero, Roberto, "La Constitución económica”, Revista Chilena de Derecho, Santiago, vol. 6, núms. 1-4, 1979, p. 80. También alguna jurisprudencia recoge la definición del OPE desde una perspectiva formal y normativa. SCA (Santiago), rol 4013-95, de 25 de mayo de 1996, en Gaceta Jurídica, Santiago, núm. 192, Legal Publishing, 1996, considerando 50., p. 30, que señala lo siguiente: "la garantía en comento forma parte del denominado «orden público económico» que ha sido definido «como el conjunto de principios y normas jurídicas que organizan la economía del país y facultan a la autoridad para regularla en armonía con los valores de la sociedad nacional formulados en la Constitución»". Igual cosa se puede apreciar en SCA (Santiago), rol 2762-91, de 15 de junio de 1992, en Gaceta Jurídica, Santiago, núm. 144, Legal Publishing, 1992, considerando 20., p. 74.

${ }^{60}$ En este sentido, Martín-Retortillo, Sebastián, Derecho administrativo económico, Madrid, Editorial la Ley, 1988, t. I, p. 185.

${ }^{61}$ Ferrada, Juan Carlos, op. cit., p. 49.
} 
Esta revista forma parte del acervo de la Biblioteca Jurídica Virtual del Instituto de Investigaciones Jurídicas de la UNAM

desde luego, su reconocimiento implícito (muchas Constituciones contemporáneas así lo hacen), sino la interpretación que se hace de ésta, en su versión más liberal y, en consecuencia, con la mercantilización de las principales y más importantes esferas de la realidad, lo que incluye la sanidad, la educación y la seguridad social.

Es probable que esta opción radical tomada por el constituyente autoritario chileno sea el resultado de una sobrerreacción a las políticas económicas que rigieron en las décadas de los sesenta y setenta en nuestro país, poniendo énfasis en la idea de que los buenos resultados económicos requieren liberalización comercial, estabilidad económica y correcta fijación de precios. Esta concepción asume que los mercados privados por sí solos son capaces de distribuir eficientemente los recursos, lo que genera un fuerte y dinámico crecimiento, sobrevalorando así la capacidad de autorregulación de los propios mercados. $^{62}$

Para materializar esta interpretación, se ha señalado que en la Constitución chilena se encuentra el principio de subsidiariedad, que conduce a comprender el rol del Estado en la economía. Es lo que llamamos la interpretación neoliberal del principio, puesto que éste conviene recordar - se encuentra también presente en los tratados de la UE y en el magisterio oficial de la Iglesia católica y su comprensión es diferente.

Tratándose de la interpretación neoliberal realizada por parte de la doctrina chilena, presenta dos notas que conviene destacar. La primera, es que basa sus postulados en una interpretación "libre" de la doctrina social de la Iglesia, y la segunda en que postula un rol abstencionista del Estado.

En relación con los fundamentos encontrados en la doctrina de la Iglesia, decimos "libre" porque los autores acomodan las posturas de la Iglesia pero sólo en cuanto se refieren al rol abstinente (o subsidiario) del Estado, pero no cuando los documentos pontificios destacan su importancia o proponen la emergencia del principio de solidaridad.

El autor más representativo de la orientación neoliberal que se funda en la doctrina social de la Iglesia es Fermandois quien, basándose en Guzmán, propone una

\footnotetext{
${ }^{62}$ Estévez Valencia, Jaime, "Visión sobre la Constitución económica”, Revista de Derecho Público, Santiago, vol. 62, 2000, p. 99; Masbernat Muñoz, Patricio y Hurtado Contreras, José Tomás, “Crítica al concepto de orden público económico", Revista de Derecho Público, Santiago, vol. 66, 2004, p. 209. No extraña, entonces, que existan autores que para explicar el actual entramado constitucional recurran a la historia económica previa para justificar la institucionalidad jurídica-económica que devino en Chile. Al respecto, Cuevas Farren, Gustavo, “Protección constitucional de la libertad económica. Notas y reflexiones", Letras Jurídicas (Revista electrónica de Derecho), Guadalajara, núm. 2, 2006, pp. 2-9, disponible en http://cuci.udg.mx/letras/sitio/index.php/revistanumero-02-primavera-marzo-septiembre-de-2006. [citado 19 de enero de 2015].
} 
interpretación del principio de subsidiariedad, que consiste en un rol abstinente de parte del Estado. Nos detenemos en este autor, ya que es el que ha desarrollado de manera más sistemática esta propuesta interpretativa, siendo, por tanto, el mejor representante de esta propuesta. Sin embargo, es posible encontrar otros autores que también postulan la comprensión del principio de subsidiariedad desde una perspectiva de Estado abstencionista. ${ }^{63}$ Lo mismo puede decirse de la jurisprudencia, que se ha hecho eco de la propuesta restrictiva para el principio de subsidiariedad. ${ }^{64}$

${ }^{63}$ Al respecto véase Bertelsen Repetto, Raúl, “El Estado empresario en la Constitución de 1980”, Revista Chilena
de Derecho, Chile, vol. 14, núm. 1, 1987, p. 123; Soto Kloss, Eduardo, Derecho administrativo. Bases
fundamentales, Santiago, Editorial Jurídica, 1996, t. II, pp. 153 y 154; Guerrero, Roberto, op. cit., pp. 88 y 89;
Bluümel Mac-Iver, José Ignacio, “El Estado empresario, su sometimiento a la legislación común y la libre
competencia”, Revista de Derecho de la Empresa, núm. 4, 2005, pp. 129, 134 y 135; Navarro Beltrán, Enrique, “E Estado empresario a la luz de la Constitución de 1980", Revista de Derecho Público, Chile, núm. 62, 2000, p. 43; Covarrubias Cuevas, Ignacio, "Subsidiariedad y Estado empresario", Revista de Derecho Público, Chile, vol. 66, 2004, pp. 253-259; Bulnes Aldunate, Luz, “Visión académica de la Constitución económica de 1980", Revista de Derecho Público, Chile, vol. 62, 2000, pp. 90 y 91; López Magnasco, Sebastián, op. cit., p. 69. Aunque sin mencionarlo expresamente, también sostiene este postulado Cuevas Farren, Gustavo, op. cit., pp. 15 y 16.

${ }^{64}$ Esta posición en relación con el principio de subsidiariedad ha sido confirmada por la jurisprudencia, tanto por los tribunales superiores de justicia como por el TC. Así, el TC ha señalado que "dentro de la filosofía económica de la Constitución de 1980, expresada en el artículo 19, núm. 21 solamente en forma muy excepcional puede el Estado desarrollar actividades empresariales, siendo la norma general que ellas queden entregadas a la acción de los particulares" (STC, rol 134, del 9 de septiembre de 1991). Esta misma hipótesis es sostenida en diversas sentencias de los tribunales de justicia, por ejemplo, "el propósito perseguido por la consagración del derecho a que se refiere el artículo 19 núm. 21 de la carta fundamental, que quiere conferir a los particulares una intervención preferente en el desarrollo de las actividades económicas, reservando, en cambio, para el Estado, sólo un rol subsidiario en ese ámbito" (SCA —Santiago—, rol 2.798-94, del 4 de julio de 1995, considerando 50., en Base de datos Legal Publishing, núm. legal publishing 13696); “son los particulares quienes tienen libertad para desarrollar actividades económicas en forma exclusiva y que el Estado sólo puede abordarlas si una ley especial, de quórum calificado así lo autoriza, esto es, por aplicación del principio de la subsidiaridad" (SCS, rol 4068-98, del 16 de enero de 1998, en Gaceta Jurídica, núm. 222, legal Publishing, Santiago, 1998, p. 56). También puede cotejarse esta interpretación en SCA (Santiago), rol 2396-91, del 5 de diciembre de 1991, en Gaceta Jurídica, núm. 138, legal publishing, Santiago, 1991, pp. 59-63; SCA (Santiago), rol 575-93, del 28 de abril de 1993, en Gaceta Jurídica, núm. 154, legal publishing, Santiago, 1991, pp. 74-78; SCA (Santiago), rol 2798-94, del 29 de noviembre de 1995, en Gaceta Jurídica, núm. 181, legal publishing, Santiago, 1995, pp. 55-58; SCS, rol 328-99, del 17 de marzo de 1999, en Gaceta Jurídica, núm. 225, legal publishing, Santiago, 1999, pp. 31-35; SCS, rol 248-00, del 13 de enero de 2000, en Gaceta Jurídica, núm. 235, legal publishing, Santiago, 2000, pp. 37-52; SCS, rol 3.573-10, del 8 de junio de 2010, en Base de datos Legal Publishing, núm. legal publishing 43987. 
Esta revista forma parte del acervo de la Biblioteca Jurídica Virtual del Instituto de Investigaciones Jurídicas de la UNAM

Para fundar su opinión, Fermandois se basa en el famoso parágrafo 80 de Quadragésimo anno, y a partir de ahí hace una explicación "del bastidor filosófico del principio de subsidiariedad". ${ }^{65}$

Este autor parte de una concepción socioantropológica, que supone la primacía del individuo por sobre la sociedad, y que es la piedra angular del ordenamiento constitucional chileno. ${ }^{66}$ Lo anterior supone que el hombre

...está destinado a una perfección metaterrenal, mientras el Estado no tiene ni aspira, como un todo, a una perfección espiritual metaterrena. El Estado se agota en el mundo; en tanto el hombre, en la totalidad de las creencias y cultos de nuestra civilización cristiano occidental, sólo prepara en este mundo su paso a la otra vida, más perfecta, en la que alcanzará su fin. ${ }^{67}$

No es de extrañar entonces la relativización de la importancia de la sociedad y, cómo no, del Estado.

Con todo, si bien la persona tiene el primado de lo real, en que lo más importante es su despliegue en libertad, no es menos cierto que el individuo es un ser social que tiende a reunirse con otros para formar agrupaciones (las sociedades intermedias, entre el individuo y el Estado). Entonces, para que el despliegue personal sea eficaz, las asociaciones han de gozar de la debida autonomía de la sociedad mayor, en este caso el Estado, para realizar los cometidos que pueden hacer por sí mismas. ${ }^{68}$

De ahí que, Fermandois señale diversos requisitos que justifican la actuación del Estado, “intervención de suyo excepcional, temporal, y revela una falla en la estructura social que

\footnotetext{
${ }^{65}$ Fermandois, Arturo, op. cit., p. 89.

${ }^{66}$ Ibidem, p. 85. Por su parte, la primacía de la persona humana también ha sido reconocida por el TC: "en lo que se refiere a la violación del derecho a desarrollar cualquiera actividad económica lícita conviene señalar que este derecho fundamental amparado y protegido por la Constitución, no es sino expresión del reconocimiento de la primacía de la persona humana y de su libre iniciativa para emprender y así realizar la plenitud de sus virtualidades para su propio bien y el de sus semejantes, colaborando en la promoción del bien común". STC, rol 226, del 8 de octubre de 1995, considerando 41.

${ }^{67}$ Fermandois, Arturo, op. cit., p. 87. Esta afirmación es sumamente discutible, incluso desde una perspectiva católica romana, pues supone un enfoque antropológico trascendente, como si la vida fuera "un valle de lágrimas". Esta concepción antropológica, previa al Concilio Vaticano II, es respondida desde concepciones que realzan la importancia de la inmanencia, por ejemplo, Bentué, Antonio, “Desafíos a la credibilidad del cristianismo", Teología yVida, Chile, vol. XLVII, núm. 1, 2006, pp. 114-118; Scannone, Juan Carlos, “La filosofía de la liberación: historia, características, vigencia actual", Teología y Vida, Chile, vol. L, núms. 1 y 2, 2009, pp. 56-73; Silva Gatica, Sergio, "Lo absoluto y lo relativo: aproximación hermenéutica”, Teología y Vida, Chile, vol. XLIX, núm. 1 y 2, 2008, pp. 203-208.

${ }^{68}$ Fermandois, Arturo, op. cit., p. 90.
} 
Esta revista forma parte del acervo de la Biblioteca Jurídica Virtual del Instituto de Investigaciones Jurídicas de la UNAM

debe en definitiva repararse". ${ }^{69}$ Sin embargo, hay ciertas esferas que o son indelegables por parte del Estado (defensa nacional, relaciones exteriores y la regulación normativa de las sociedades intermedias) o implican una intervención de su parte ante a la ausencia o falta de interés de la iniciativa privada. ${ }^{70}$

Y para justificar la importancia del principio de subsidiariedad, pero desde su particular punto de vista, el autor citado alude a la UE como una organización que

...abrazó la subsidiariedad como única forma de coordinar el ejercicio de potestades confluyentes en un ente multilateral cada vez más numeroso... el ejemplo de la UE, con sus fines primeramente económicos, pero políticos a fin de cuentas, demuestra que este natural principio filosófico orienta desde la más pequeña de las sociedades intermedias, hasta la más portentosa organización política humana. ${ }^{71}$

Aun cuando no lo señala Fermandois, conclusión inevitable de una propuesta de esta naturaleza es la entrega de todos los sectores sociales a la regulación económica por los particulares, incluidas actividades sensibles, como la educación, la vivienda, la sanidad, la seguridad social, el transporte, etcétera, porque finalmente todas las esferas del mundo de la vida pueden ser asumidas por la iniciativa económica privada, y Guzmán expresamente así lo señala: "la subsidiariedad es aplicable a todos los campos de la vida social". ${ }^{72}$ Incluso para el caso de la educación, Guzmán es de la idea de que se “debe estimular a los

\footnotetext{
${ }^{69}$ Ibidem, p. 90. Los requisitos son: a) que se trate de actividades, fines o bienes particulares convenientes para el bien común; b) que los particulares no estén logrando en un nivel adecuado dichos fines o bienes particulares, o no exista en dicha área presencia alguna de particulares; y, c) que el Estado haya agotado todo su esfuerzo para que los particulares asuman tales actividades. Una vez producida la intervención estatal, nacen dos obligaciones: a) el Estado debe desempeñar las tareas subsidiarias estimulando siempre a los particulares a que suplan el vacío social cuanto antes y en la mayor medida posible; b) el Estado debe retirarse y cesar su intervención el momento mismo en que los particulares asuman las actividades subsidiadas. Ibidem., pp. 90 y 91.

${ }^{70}$ Fermandois, Arturo, op. cit., pp. 91 y 92.

${ }^{71}$ Ibidem, p. 95. Particular resulta su interpretación, pues pretende persuadirnos de que la comprensión del contenido de este principio en la UE es similar a su propuesta, en circunstancias que la subsidiariedad en el derecho europeo se relaciona con temas competenciales e incluso con un mejoramiento del sistema democrático.

72 Rojas Sánchez, Gonzalo, Derecho político. Apuntes de las clases del profesor Jaime Guzmán Errázuriz, Santiago, Ediciones Universidad Católica de Chile, 1996, p. 56. Para el caso concreto de la salud dice Guzmán que "el que un porcentaje mayoritario de las acciones de salud —o de cualquier otra actividad- sean ejercidas en un país por el Estado, no implica el quebrantamiento del principio de subsidiariedad, sino la aplicación de él, en cuanto ello sea claramente necesario en la realidad social vigente, y en cuanto el Estado realice todo su esfuerzo posible para que esa deficiencia se supere gradualmente". Ibidem, p. 56.
} 
particulares para que inicien nuevas escuelas, y así ir desapareciendo [el Estado] poco a poco. Debe aspirar a no tener ninguna". ${ }^{73}$ Como afirma López Magnasco, "la subsidiariedad exige una abstención del Estado en todo aquello que pueden realizar las sociedades menores... en que el Estado debe actuar cuando los entes menores no pueden o no quieren realizar dichas actividades". ${ }^{74} \mathrm{Y}$ estas premisas constituyen el núcleo de la interpretación de este principio desde la perspectiva neoliberal. Mas se trata de una propuesta que por su radicalidad debe ser relativizada y dar paso a una interpretación más razonable y comprehensiva de las diferentes sensibilidades que sobre la materia existen en una sociedad democrática, como lo veremos en el siguiente apartado.

Por lo tanto, la Constitución económica chilena pareciera poner el acento en que la función de lo colectivo y del Estado es asegurar que el interés privado se concrete en todos los individuos, creando las condiciones para que éstos se puedan desarrollar plenamente en lo material. ${ }^{75}$ Así, bajo esta perspectiva, no hay interés colectivo más allá de la suma de intereses individuales, los que serán el objetivo preferente de toda la arquitectura constitucional.

\section{PROPUESTA DE REINTERPRETACIÓN DE LA CONSTITUCIÓN ECONÓMICA CHILENA}

Como se ha señalado, una Constitución económica es una figura con techo ideológico abierto, propio de un sistema democrático, que se funda en acuerdos entre diversos actores que pueden fundar sus pretensiones en diferentes cosmovisiones. Por lo mismo, éste será un espacio "en que el elemento esencial es definir el mínimum constitucional de reglas y principios del sistema. Asimismo, entre la libertad económica y la intervención del Estado existe una amplia gama de políticas económicas concretas". ${ }^{76}$

Por tanto, se impone la imperiosa necesidad de reinterpretar la Constitución Política dictada en 1980 con base en criterios teleológicos, que consideren el carácter evolutivo de la realidad social que está llamada a regular. Se trata en el fondo de superar, en ésta como en otras materias constitucionales, el originalismo interpretativo que ha caracterizado a nuestra doctrina en los últimos 30 años, que se expresa en el mecanismo habitual de

\footnotetext{
${ }^{73}$ Ibidem, p. 61.

${ }^{74}$ López Magnasco, Sebastián, op. cit., p. 44.

${ }^{75}$ Avilés Hernández, Víctor, op. cit., p. 338.

${ }^{76}$ Zúñiga Urbina, Francisco, “Constitución económica y Estado empresario”, Revista de Derecho Público, Santiago, núm. 63, 2001, p. 343.
} 
Esta revista forma parte del acervo de la Biblioteca Jurídica Virtual del Instituto de Investigaciones Jurídicas de la UNAM

acudir a las actas de la Comisión de Estudios para comprender el significado de las disposiciones de la Constitución vigente, en este caso, en la Constitución económica. ${ }^{77}$

Si esto es así, resulta imperioso, en primer lugar, relativizar la radical propuesta interpretativa del principio de subsidiariedad. En efecto, la postura neoliberal interpreta parcial e insuficientemente la doctrina social de la Iglesia, que es la principal fuente de la cual se nutre esta propuesta. Con todo, es necesario advertir que la fundamentación en la doctrina cristiana presenta el inconveniente de que colisiona con la natural pluralidad política que existe en una sociedad, y esta doctrina, por razonable que sea, es sólo una vertiente entre otras.

Aun así, la exégesis que hacen los autores que defienden el abstencionismo del Estado interpretan la doctrina de la Iglesia de manera parcial, porque en esta búsqueda de razonabilidad sustantiva (y legítima) que dé razón a sus dichos, omiten — no sabemos si deliberadamente o por ignorancia - la referencia al principio de solidaridad presente en los documentos pontificios, principio este último que ha de suponer un papel significativo por parte del Estado en la marcha de la economía.

El núcleo esencial del principio de subsidiariedad para el magisterio oficial de la Iglesia consiste en el respeto por parte del Estado a la libertad de iniciativa de los particulares y de las comunidades que surgen al interior de la sociedad, y en que aquél no debe realizar aquellas actividades que las comunidades intermedias son capaces de llevar adelante. Sin embargo, si se detecta la insuficiencia de los grupos intermedios para la satisfacción de una necesidad socialmente relevante, debe ser el Estado el que asuma su ejecución. Y éste deber se basa en el propio contenido del principio de subsidiariedad, el cual es modelado por el principio y deber de solidaridad. ${ }^{78}$

Por ello, esta doctrina no puede ser entendida como una propuesta de un Estado ausente. Como señala Bidart Campos, "la presencia rectora del Estado en el campo de la misma actividad (la económica), sin exagerar su intervención pero, también, sin sacralizar al mercado y a la competencia, debe coordinar todo cuanto circunstancialmente haga falta,

\footnotetext{
${ }^{77}$ Masbernat Muñoz, Patricio y Hurtado Contreras, José Tomás, op. cit., p. 212. En todo caso, en esta investigación recurrimos a las actas de la Comisión, no tanto por encontrar una interpretación satisfactoria a las demandas de la Constitución, sino porque en ese trabajo encontramos la fuente de inspiración para muchas interpretaciones de la Constitución que persisten en la actualidad. No es que intente realizar una labor de deconstrucción, pero mi acercamiento a ellas es crítico.

${ }^{78}$ Loo Gutiérrez, Martín, “La disciplina constitucional del principio de subsidiariedad en Italia y Chile”, Revista de Derecho (Valparaíso), vol. XXXIII, 2009, p. 421. Recordemos también el § 15, párrafo penúltimo de la encíclica Centesimus annus de Juan Pablo II.
} 
Esta revista forma parte del acervo de la Biblioteca Jurídica Virtual del Instituto de Investigaciones Jurídicas de la UNAM

porque es indeclinable su gestión promotora del bienestar generaly del desarrollo humano. Esto no es dirigismo colectivista, ni '/aissez faire' liberal". ${ }^{79}$

Pero si incluso concedemos que el principio de subsidiariedad encuentra su fundamento en la doctrina social de la Iglesia a la manera como lo entiende Fermandois y otros, con base en la lectura realizada de las actas de la Comisión de la Nueva Constitución, este argumento de naturaleza originalista colisiona con las características de un sistema democrático, en que la cosmovisión religiosa representada por el catolicismo es una entre muchas otras expresiones religiosas. Y además, es contrafáctica, porque de un tiempo a esta parte, esa visión política impuesta hace más de 30 años ha sido moderada especialmente por la comunidad política —el pueblo de Chile- los que al parecer no comparten esa posición, lo cual ha de traducirse en una presencia del Estado activa en sectores sensibles para la marcha de la sociedad. ${ }^{80}$

En segundo lugar, incluso desde una interpretación teleológica, consagrar el sistema de mercado supone ya ciertos límites básicos, por exceso y por defecto. Por exceso, si la Constitución económica es de techo ideológico abierto, no debiera admitir un sistema de mercado puro, con una economía altamente liberalizada. Por defecto, no puede desnaturalizarse el mercado de manera tal que devenga en una economía completamente planificada y centralizada. Así, hay intervención de los poderes públicos, pero el corazón del modelo descansa en la iniciativa privada. En este sentido, como señala Martín-Retortillo, si la Constitución consagra una economía de mercado, "en modo alguno caben en ella todas las opciones; no obstante, su aplicación práctica y su desarrollo es marcadamente flexible y puede presentar distintas y diferentes versiones". ${ }^{81}$

En este contexto, pareciera necesario en el derecho chileno huir de la opción seguida por algunos autores de sacralizar las bondades de la mercantilización del mundo de la vida, reconociendo que en un Estado democrático moderno le corresponden a éste ciertas

\footnotetext{
${ }^{79}$ Bidart Campos, Germán, El orden socioeconómico en la Constitución, Buenos Aires, Ediar, 1999, p. 120 (cursiva en el original).

${ }^{80}$ Mayol, Alberto, El derrumbe del modelo. La crisis de la economía de mercado en el Chile contemporáneo, 2a. ed., Santiago, Lom, 2012; Atria, Fernando, op. cit. El programa de gobierno por el cual fue electa la actual presidenta de la República, Michelle Bachelet, se funda en tres pilares: reforma tributaria, reforma educativa y reforma constitucional, los cuales no son sino reflejo del malestar ciudadano, que se expresa en multitudinarios movimientos sociales, que pusieron en tensión las actuales (y radicales) características del modelo de desarrollo chileno, movimientos que parten con los estudiantes en 2011. Sobre el programa, Programa de Gobierno Michelle Bachelet (2014-2018), disponible en http://michel/ebachelet.cl/programa.

${ }^{81}$ Martín-Retortillo, Sebastián, op. cit., p. 72.
} 
actividades económicas, especialmente en función del respeto y promoción de los derechos sociales y de la superación de la pobreza. Así, se puede sostener que el Estado no puede ya desentenderse de ciertas necesidades sociales, que dejadas al libre arbitrio de la iniciativa privada tal vez no llegarían nunca a satisfacerse en plenitud, ya que las obligaciones y tareas que le impone la realidad actual exige una actividad más intensa en la regulación del mercado y la actividad económica

De este modo, si bien es posible afirmar que la Constitución económica chilena establece claramente una opción por la economía de mercado, su concreción "dentro de ese marco, admite variables, que en cada momento se concretan conforme a la 'ideología' económica de los distintos y sucesivos detentadores del poder". ${ }^{2}$ Ello es posible inferirlo incluso del propio texto constitucional vigente, ya que más allá de sus normas, también es posible encontrar en éste la consagración de valores y principios, por ejemplo, la promoción de los derechos sociales (muchos de ellos establecidos en el artículo 19), asociados a la dignidad de la persona (artículo 5o.), el bien común como un fin del Estado, - la primacía de la persona humana, pero entendida como una conquista propia de la época moderna, que implica emancipación de figuras autoritarias, y que al mismo tiempo reclama la protección del individuo.

Además, el concepto de Constitución económica es contingente y se desarrolla bajo un lenguaje equívoco, generándose la imposibilidad de predicar certeza y estabilidad de su significación axiológica, lo que no implica su inutilidad, puesto que se puede reorientar su comprensión hacia principios alternativos mediante una labor interpretativa. ${ }^{83}$ Así, la apertura de los conceptos constitucionales unida a una lectura dinámica de la sociedad y la Constitución permite que la interpretación pueda ir adaptándose a las cambiantes circunstancias sociales, políticas o económicas, y evitar el peligro de una petrificación del derecho, peligro latente y del que no pocas veces pecan los sistemas. Que la realidad social va cambiando no es un descubrimiento copernicano. La dificultad estriba en una lectura adecuada de la realidad y de la necesaria adaptación a los tiempos nuevos.

En este sentido, puede ser interesante traer a colación uno de los criterios interpretativos del Código Civil español, que en su artículo 3.1 señala que "las normas se interpretarán según el sentido propio de sus palabras, en relación con el contexto, los antecedentes históricos y legislativos, y la realidad social del tiempo en que han de ser

\footnotetext{
${ }^{82}$ Idem.

${ }^{83}$ Pereira Fredes, Esteban, “Orden público económico: una propuesta de conceptualización”, Derecho y Humanidades, Santiago, núm. 13, 2008, p. 170.
} 
aplicadas, atendiendo fundamentalmente al espíritu y finalidad de aquéllas". En palabras de Diez-Picazo, de lo que se trata es de que "la aplicación de la ley no vaya contra la realidad social en el tiempo en que se efectúa, que puede ser distinta de la que existía cuando se promulgó", ${ }^{84}$ y la realidad que va cambiando está relacionada con paradigmas de diversa naturaleza, que son "factores políticos, sociales, económicos, culturales, estados de conciencia u opinión pública, y convicciones y creencias imperantes en un momento dado en determinada sociedad". ${ }^{55}$ Por ello, la norma se relativiza desde la perspectiva de la evolución social, porque efectivamente se puede producir un desajuste entre norma y realidad.

En todo caso, lo anterior no supone una modificación de las normas legales, sino que es una actualización que reconoce límites en el texto normativo. Su práctica requiere de mucha prudencia, toda vez que está latente el peligro de la arbitrariedad al entregar a la subjetividad del juez delicadas apreciaciones, como aquellas ligadas a la conciencia moral de un pueblo. Sin embargo, cuando se trata de esferas de la realidad más nebulosas o en vías de formación, la búsqueda de soluciones por parte del intérprete es más libre. ${ }^{86}$

Por ello, resulta razonable que el sistema jurídico se manifieste abierto a esta problemática y generar la flexibilización de los criterios hermenéuticos. Si bebemos de una escuela de hermenéutica constitucional flexible, las cláusulas abiertas pueden ser determinadas evolutivamente en su contenido material, pero si nuestra referencia es rígida, quedaremos atrapados por la tradición y por los contenidos políticos del momento inicial del pacto, por más razonables que sean.

Por último, pareciera ser necesario en este contexto avanzar hacia una definición expresa de la sociabilidad del Estado, en que la fórmula Estado social, como concepto ampliamente aceptado por las democracias contemporáneas, cumpla una función hermenéutica que permite la comprensión y actualización de los postulados del Estado. La cláusula del Estado social, al figurar en la Constitución, excluye una interpretación radicalmente individualista de los derechos fundamentales, lo que supone "adecuar el disfrute efectivo de los diferentes derechos a las posibilidades reales de cada sector de la sociedad, reforzando, sí, unas veces su aprovechamiento en referencia a los sectores

\footnotetext{
${ }^{84}$ Diez-Picazo, Luis y Gullón, Antonio, Sistema de derecho civil, 11a. ed., Madrid, Tecnos, p. 170. También puede verse Gullón Ballesteros, Antonio, “Comentarios al artículo 3 del Código Civil”, en Sierra Gil de la Cuesta, I. (coord.), Comentario del Código Civil, Barcelona, Bosch, 2000, t. I, pp. 369-378.

${ }^{85}$ Diez-Picazo, Luis y Gullón, Antonio, op. cit., p. 170.

${ }^{86}$ Ibidem, pp. 170 y 171.
} 
Esta revista forma parte del acervo de la Biblioteca Jurídica Virtual del Instituto de Investigaciones Jurídicas de la UNAM

menos privilegiados, pero también restringiendo otras el alcance el alcance de esos derechos (función social de la propiedad...) en razón de la posición social prevalente de sus titulares". ${ }^{87}$

En este marco, pareciera indispensable la apertura de los conceptos constitucionales contenidos en la Constitución chilena dictada en 1980, lo que unido a una lectura de la sociedad y la Constitución dinámicas permitiría que la interpretación pueda ir adaptándose a las cambiantes circunstancias sociales, políticas o económicas, evitando el peligro de una petrificación del derecho.

\section{CONCLUSIONES}

1. Es necesario revisar las concepciones teóricas tradicionales que se utilizan para interpretar la Constitución chilena, que a pesar de los años transcurridos desde su promulgación, siguen vigentes a pesar de la falta de consenso al respecto; no se trata de teorías que habitan en los extramuros de la sociedad, sino que son fuente que da origen y sustento al entramado económico y social de la Constitución chilena.

2. La Constitución económica chilena no es neutra, sino que cuenta con supuestos que la fundan, entre los que destaca la economía de mercado y un rol precario para el Estado como agente económico. En este caso, los desafíos que debe enfrentar nuestra Constitución son significativos.

3. Por de pronto, es necesaria una reinterpretación del principio de subsidiariedad, el que carece de una interpretación unívoca. El problema radica que en Chile, este principio ha sido interpretado desde su configuración negativa; es decir, un Estado abstencionista, teniendo como soporte las reflexiones contenidas en la doctrina social de la Iglesia.

4. Esta revisión de la interpretación tradicional de nuestro modelo de Constitución económica no significa relevar a los particulares y a las sociedades intermedias de su necesaria iniciativa, en ningún caso. Es más, la iniciativa económica privada será vital para el desarrollo y crecimiento de un país. La exigencia radica más bien en una necesaria reinterpretación del principio de subsidiariedad, ya que la fórmula tradicional ha llevado a la construcción de un modelo de desarrollo original y que reclama atenuaciones.

5. Es necesario asumir el carácter abierto de algunas instituciones que fundan el sistema económico presente en la Constitución. En principio, las cláusulas abiertas, pues se

\footnotetext{
${ }^{87}$ Garrorena Morales, Antonio, El Estado español como Estado social y democrático de derecho, Madrid, Tecnos, 1987, p. 102.
} 
Esta revista forma parte del acervo de la Biblioteca Jurídica Virtual del Instituto de Investigaciones Jurídicas de la UNAM

encuentran condicionadas por su contexto (por ejemplo las del artículo 19 núm. 21 o la función social de la propiedad, artículo 19 núm. 24), pero también la comprensión de lo que es una economía de mercado y el rol del Estado en la economía.

5. Finalmente, no desconocemos la importancia de la economía de mercado; sin embargo, no hay una sola manera de comprenderla, ya que su entendimiento está condicionado por las fuentes de las cuales se bebe, que son reflejo de la tensión libertad-igualdad. Es cierto, hay elementos nucleares como el intercambio y la competencia, pero el mayor desafío radica en otorgarle al Estado un lugar como colaborador en la marcha de la economía.

\section{BIBLIOGRAFÍA}

Alberti Rovira, Enoch, Autonomía política y unidad económica, Madrid, Civitas, 1995.

Amin, Samir, El capitalismo en la era de la globalización, Buenos Aires, Paidós, 1999.

ARAGón, Manuel, “Constitución económica y libertad de empresa”, Estudios jurídicos en homenaje al profesor Aurelio Menéndez, Madrid, Civitas, 1996, t. I.

ARIÑo ORTIZ, Gaspar, “La iniciativa pública en la Constitución. Delimitación del sector público y control de su expansión", Revista de Administración Pública, Madrid, núm. 88, 1979.

ATRIA, Fernando, Veinte años después, neoliberalismo con rostro humano, Santiago, Catalonia, 2013.

Avilés HeRnÁNDEZ, Víctor, "Orden público económico: noción crítica”, Revista de Derecho Público, Santiago, núm. 63, 2001.

Bassa Mercado, Jaime, La teoría del poder constituyente en la Constitución chilena vigente, tesis para optar al grado de magíster en derecho, Santiago, Universidad de Chile, Facultad de Derecho, 2007.

BASSOLS ComA, Martín, Constitución y sistema económico, Madrid, Tecnos, 1988.

BeltrÁn De FeliPE, Miguel, Originalismo e interpretación, Dworkin vs. Bork: una polémica constitucional, Madrid, Publicaciones de la Facultad de Derecho-Universidad Complutense-Civitas, 1989.

BentuÉ, Antonio, "Desafíos a la credibilidad del cristianismo", Teología y Vida, Chile, vol. XLVII, núm. 1, 2006.

Bertelsen Repetto, Raúl, “El Estado empresario en la Constitución de 1980", Revista chilena de Derecho, Chile, vol. 14, núm. 1, 1987. 
Esta revista forma parte del acervo de la Biblioteca Jurídica Virtual del Instituto de Investigaciones Jurídicas de la UNAM

BIDART CAMPOS, Germán, El orden socioeconómico en la Constitución, Buenos Aires, Ediar, 1999.

- - - “La Constitución económica (un esbozo desde el derecho constitucional argentino), Cuestiones Constitucionales, México, UNAM, núm. 6, 2002.

BLUÜMEL MAC-IVER, José Ignacio, “El Estado empresario, su sometimiento a la legislación común y la libre competencia", Revista de Derecho de la Empresa, núm. 4, 2005.

BÖCKENFÖRDE, Ernest, “El poder constituyente del pueblo. Un concepto límite del derecho constitucional", en Böckenförde, Ernest, Estudios sobre el Estado de derecho y la democracia, Madrid, Trotta, 2000.

BREY BlANCO, José Luis, "Ideologías políticas y modelo socioeconómico constitucional”, El sistema económico en la Constitución española, Madrid, XV Jornadas de Estudio de la Dirección General del Servicio Jurídico del Estado, Ministerio de Justicia, 1994.

BREWER-CARÍAS, Allan, "Reflexiones sobre la Constitución económica", Revista de Derecho Público, Caracas, núm. 43, 1990.

Bulnes AldunAte, Luz, “Visión académica de la Constitución económica de 1980”, Revista de Derecho Público, Chile, vol. 62, 2000.

CANCIO MeliÁ, Jorge, “La Constitución económica: promesas incumplibles”, Revista jurídica, Madrid, núm. 7, 2002.

CANTARO, Antonio, "El declive de la Constitución económica del Estado Social", en GARCÍA Herrera, Miguel (dir.), El constitucionalismo en la crisis del estado social, Bilbao, UPV, 1997.

CASCAJO CASTRO, José Luis, "El Estado democrático: materiales para un léxico constitucional español", Revista Española de Derecho Constitucional, Madrid, núm. 69, 2003.

CovarRUBias CUevas, Ignacio, "Subsidiariedad y Estado empresario", Revista de Derecho Público, Chile, vol. 66, 2004.

Cuevas Farren, Gustavo, "Protección Constitucional de la libertad económica. Notas y reflexiones", Letras Jurídicas (Revista electrónica de Derecho), Guadalajara, núm. 2, 2006, disponible en http://cuci.udg. $m x / /$ etras/sitio/index.php/revista-numero-02-primaveramarzo-septiembre-de-2006. [citado 19 de enero de 2015].

DiEz-PICAZO, Luis-Gullón, Antonio, Sistema de derecho civil, 11a. ed., Madrid, Tecnos.

Duque Domínguez, Justino, "Iniciativa privada y empresa", en SÁNCHEZ AGESTA, Luis (coord.), Constitución y economía, Madrid, Centro de Estudios y Comunicación Económica, 1977. 
Esta revista forma parte del acervo de la Biblioteca Jurídica Virtual del Instituto de Investigaciones Jurídicas de la UNAM

DougnaC RodRígueZ, Fernando, “La garantía constitucional del núm. 21 del artículo 19 de la Constitución en relación con las demás que configuran el «Orden Público Económico»", Gaceta Jurídica, Santiago, núm. 68, Editorial Jurídica Ediar-Conosur, 1986.

ENTRENA Cuesta, Rafael, “El modelo económico de la Constitución”, en EnTREnA CUesta, Rafael, La empresa en la Constitución española, Pamplona, Aranzadi, 1989.

ESTÉVEZ VALENCIA, Jaime, "Visión sobre la Constitución económica", Revista de Derecho Público, Santiago, vol. 62, 2000.

FerRAdA, Juan Carlos, “La Constitución económica de 1980. Algunas reflexiones críticas", Revista de Derecho (Valdivia), vol. XI, 2000.

FERMANDOIS, Arturo, Derecho constitucional económico, 2a. ed., Santiago, Ediciones Universidad Católica de Chile, 2006, t. I.

_-_, "El orden público económico bajo la Constitución de 1980", Ius Publicum, Santiago, núm. 4, 2000.

García-Pelayo, Manuel, “Consideraciones sobre las cláusulas económicas de la Constitución", en ——, Obras completas, Madrid, Centro de Estudios Constitucionales, 1991, vol. III.

García BelAunde, Domingo, Teoría y práctica de la Constitución peruana, Lima, Ediciones JV, 1993, t. II.

García Cotarelo, Juan, “El concepto de Constitución económica y su aplicación a la Constitución española de 1978", El sistema económico en la Constitución española, Madrid, XV Jornadas de Estudio de la Dirección General del Servicio Jurídico del Estado, Ministerio de Justicia, 1994.

García ECheVArRÍA, Santiago, “El orden económico en la Constitución”, Libre empresa, Madrid, núm. 8, 1978.

Garrorena Morales, Antonio, el Estado español como Estado social y democrático de derecho, Madrid, Tecnos, 1987.

Gimeno Feliú, José María, “Sistema económico y derecho a la libertad de empresa versus reservas al sector público de actividades económicas", Revista de administración pública, núm. 135, 1994.

GUERRERO BECAR, José Luis, “La libertad para desarrollar actividades económicas del artículo 19 núm. 21 y la Constitución económica", Persona y Sociedad, Santiago, vol. IV, núm. 3, 2000. 
Esta revista forma parte del acervo de la Biblioteca Jurídica Virtual del Instituto de Investigaciones Jurídicas de la UNAM

Guerrero, Roberto, “La Constitución económica”, Revista Chilena de Derecho, Santiago, vol. 6, núms. 1-4, 1979.

Gullón Ballesteros, Antonio, “Comentarios al artículo 3o. del Código Civil”, en SierRa Gil De LA CuestA, I. (coord.), Comentario del Código Civil, Barcelona, Bosch, 2000, t. I.

HÄBERLE, Peter, El Estado constitucional, México, UNAM, 2003.

Herrero de Miñón, Miguel, “La Constitución económica: desde la ambigüedad a la integración", Revista española de Derecho Constitucional, Madrid, núm. 57, septiembrediciembre de 1999.

HESSE, Konrad, “Concepto y cualidad de la Constitución”, en HESSE, Konrad, Escritos de derecho constitucional, Madrid, CEPC, 1983.

KALYVAS, Andreas, "Soberanía popular, democracia y el poder constituyente", Política y gobierno, México, vol. XII, núm. 1, 2005.

LASSALLE, Ferdinand, ¿Qué es una Constitución?, Barcelona, Ariel, 1997.

LOO GUTIÉRREZ, Martín, “La disciplina constitucional del principio de subsidiariedad en Italia y Chile", Revista de Derecho (Valparaíso), vol. XXXIII, 2009.

LÓPEZ MAGNASCO, Sebastián, Garantía constitucional de la no discriminación económica, Santiago, Editorial Jurídica, 2006.

- - L Libertad de empresa y no discriminación económica, Santiago, Cuadernos del Tribunal Constitucional, 2012.

MARTín-Retortillo, Sebastián, Derecho administrativo económico, Madrid, Editorial la Ley, 1988, t. I.

Masbernat Muñoz, Patricio y Hurtado Contreras, José Tomás, "Crítica al concepto de orden público económico", Revista de Derecho Público, Santiago, vol. 66, 2004.

MAYOL, Alberto, El derrumbe del modelo. La crisis de la economía de mercado en el Chile contemporáneo, 2a. ed., Santiago, Lom, 2012.

MontT DubouRnAIS, Luis, “El orden público económico y la Constitución”, Revista de Derecho Económico, Santiago, núms. 60 y 61, 1983.

NAVARRo Beltrán, Enrique, "El Estado empresario a la luz de la Constitución de 1980", Revista de Derecho Público, Chile, núm. 62, 2000.

Pereira Fredes, Esteban, “Orden público económico: una propuesta de conceptualización”, Derecho y Humanidades, Santiago, núm. 13, 2008. 
Esta revista forma parte del acervo de la Biblioteca Jurídica Virtual del Instituto de Investigaciones Jurídicas de la UNAM

POWELL, Jefferson, "The Original Understanding or Original Intent", Harvard Law Review, Estados Unidos de América, vol. 98, 1985.

Ojeda MARÍn, Antonio, El contenido económico de las Constituciones modernas, Madrid, Instituto de Estudios Fiscales, 1990.

QuAdRA-SALCEDo, Tomás de la, "La Constitución económica de España", en AlzaGa VillamiL, O., Comentarios a la Constitución española de 1978, Madrid, Cortes Generales, Editoriales de Derecho reunidas, 1996.

RojAS SÁnCHEZ, Gonzalo, Derecho político. Apuntes de las clases del profesor Jaime Guzmán Errázuriz, Santiago, Ediciones Universidad Católica de Chile, 1996.

SANTA María De la Vega, Raúl, "El orden económico", Revista de Derecho Económico, Santiago, núms. 60 y 61, 1983.

SCANNONE, Juan Carlos, "La filosofía de la liberación: historia, características, vigencia actual”, Teología y vida, Santiago, Pontificia Universidad Católica de Chile, vol. L, núms. 1 y 2, 2009.

Schmitt, Carl, La defensa de la Constitución, Madrid, Tecnos, 1983.

Silva GATICA, Sergio, "Lo absoluto y lo relativo: aproximación hermenéutica”, Teología y vida, Santiago, Pontificia Universidad Católica de Chile, vol. XLIX, núms. 1 y 2, 2008.

SмIтH, Peter, "How Different are Originalism and Non-Originalism?", Hastings Law Review, vol. 65, 2011.

SоTо KLOSS, Eduardo, “La actividad económica en la Constitución Política de la República de Chile (la primacía de la persona humana)", Ius Publicum, Santaigo, núm. 2, 1999.

__-, Derecho administrativo. Bases fundamentales, Santiago, Editorial Jurídica, 1996, t. II.

Streeter Prieto, Jorge, "El paradójico orden público económico", Revista de Derecho Económico, núms. 60 y 61, 1983.

VARELA DEL SOLAR, José Luis, “Subsidiariedad, orden público económico y seguridad nacional en la Constitución de 1980", Revista Chilena de Derecho, Santiago, vol. 16, núm. 2, 1989.

ZAgreBelSky, Gustavo, El derecho dúctil. Ley, derechos, justicia, 5a. ed., Madrid, Trotta, 2003.

ZÚÑIGA URBINA, Francisco, “Constitución económica y Estado empresario", Revista de Derecho Público, Santiago, núm. 63, 2001. 